\title{
REATTACHMENT OF FRACTURED PERMANENT INCISORS IN SCHOOLCHILDREN (REVIEW)
}

\author{
Ani Belcheva \\ Department of Pediatric Dentistry, Faculty of Dental Medicine, \\ Medical University, Plovdiv, Bulgaria
}

\section{SUMMARY:}

Crown fractures as a part of traumatic injuries are common among schoolchildren. They create serious functional, esthetic and psychological problems for both children and their parents. Repeated reconstructions are needed in many cases because of compromised results as time passed by. The clinicians find it difficult because of the small patient's age, need of high esthetics in the front region and the choice of exact treatment plan.

In this review article the method of reattaching fractured incisors has been described. A critical analysis of proposed from different authors improvements and objections has been made. All the advantages and evidences described in the literature are discussed in order to give the clinician a good therapeutic approach.

Key words: reattachment, crown fractures, permanent teeth

\section{INTRODUCTION}

Trauma to the permanent teeth is rather common event among schoolchildren. Crown fracture present almost $92 \%$ of all traumatic injuries of the permanent teeth. The anterior incisors are most often affected $(80 \%$ central incisors and $16 \%$ lateral incisors) because the anterior position of the maxilla and tooth protrusion.

Reconstruction of crown fractures has developed through the years. Elaboration in the field of adhesive dentistry gives opportunity to the clinicians to have minimal invasive approach and achieve esthetic and functional restoration of the fractured tooth. Development of the adhesive materials creates new perspectives in reconstruction of fractured teeth $(6,36)$.

The aim of this review article is to propose the method reattachment of the original tooth fragment for reconstructing crown fractures of permanent incisors.

Chosack and Eildeman describe for the first time in 1964 reattachment of tooth fragment after trauma of 12 years old child (13). They suggest fixation of post in the root canal after endodontic treatment and reattached to it the coronary fragment. They find this reconstruction as temporary before introduction of adhesive dentistry.

Andreasen FM et al. make a detailed description of the clinical protocol when treating uncomplicated and complicated crown fractures by reattachment (3). The authors apply the so cold GLUMA protocol for reattaching of 76 permanent teeth of schoolchildren.

There are many studies published at late 80 -s and 90s describing successful clinical cases with reattached fractured incisors. Some authors apply different tooth beveling (27), others describe resources for pulp protection $(16,22)$, preparation of circumferential chamfer (5) and only adhesive reattachment (6). These clinical cases follow up reattached teeth from 3 month to 3 years and are definitely positive concerning retention and esthetics achieved.

\section{- Advantages}

Reattachment should be first choice when reconstructing fractured teeth and the fragment is available. This method has a number of advantages shown in clinical and experimental studies.

Reattached fragment to a great extent restores esthetics, as it uses the original tooth's shape, color, translucence and surface structure (31).

Reattachment of tooth fragment of anterior teeth is easy to practice and economic method that has the potential to assume the incisal strength during tooth functioning. The method ensures increased wearing steadiness and thus creates better function (12). Other advantages of this method are the psychological comfort of patient, less time spent in dental chair, exact reconstruction of tooth's morphology and usage of structure that wears out as the antagonists $(25,36)$.

Occlusal forces, generated at protrusive movements of the mandible are extremely destructive to the relation tooth fragment - bonding agent (14). That is why many authors consider placement of porcelain or composite veneers after reattachment will increase strength of these teeth to values close to the intact teeth $(14,26$, and 32$)$.

\section{- Evidence for application}

Reattachment of tooth fragment is possible on its presence after the trauma and the fragment is intact with good adaptation to the remaining tooth.

The successful reattachment depends on fragment's extend of dehydration. The longer the fragment remains dehydrated the poor tooth's strength will be. Improvement of tooth's resistance can be achieved by fragment rehydration. 
Farik et al. (18) analyze the strength of reattached fractured teeth dehydrated for a period from 5 seconds to 24 hours. Fragments dehydrated for more than 1 hour significantly decreases its fracture resistance. At the same time teeth reattached with fragments dehydrated for 24 hours and rehydrated in water for at least one day and night (the same period of time), didn't lose its strength. The result is probably due to share bond strength when the dentin is wet. Dentin's dehydration causes collapse of collagen fibers and obstruction of adequate resin monomers' penetration, leading to a poor adhesion between dentin and composite material (28).

A lasting dehydration of tooth's fragment can cause disturbance of the esthetics as the longer dehydration of the fragment is, the greater probability for not matching the original tooth's color will be. In most cases dehydrated fragment is lighter than the remained after the fracture remnant. Return of the natural color may need time or may never occur (6).

In a contemporary experimental study of Capp et al. is shown that wetness necessary for correct functioning of the adhesive mechanism is more critical for the dentin than for the enamel. Dentin removing before reattachment doubles the fracture resistance in the group of reattached fragments dehydrated for 48 hours. Same authors comment return of share bond strength after only 30 minutes of redydration before fragment reattachment. It is very useful fact that makes easier the clinical procedures (11).

Besides fragment's rehydration another important condition is its adaptation to the tooth's remnant. Performance of the technique becomes complicated when there is more than one fragment that must be connected to each other and then reattached to the tooth. Reconstruction with resin is a better therapeutic decision when there isn't good adaptation between the fragment/fragments and the remaining tooth (21).

Cooperation of the patients, that most often are between 7 and 11 years old, is necessary condition for successful reconstruction of crown fractures by fragment reattachment (25). According to Basuttil and Fung, when the child's age shows immature development of the fractured tooth's gingival margins, the application of more conservative methods for reconstruction, as reattachment, are desirable. (7).

- Techniques for preparation and adhesive materials

Fracture strength of reattached fragment can not reach that of the intact teeth (4). Another statement says that fracture strength of reattached fragment may approximate this of not fractured teeth according to the materials used and techniques performed (30). There is no negotiation in the available literature for the best preparation technique for reattachment. Most experimental studies in that field which give the bases for clinical realization are performed by Farik, Worthington and Reis. Authors propose different preparation techniques of the fragment and the remaining tooth that have vital importance for fracture resistance (8).

Besides the great amount of publications $(5,9$, and 33 ), presenting different approaches for preparation of the fractured fragment there is no study announcing long lasting result of some of the preparations. The contemporary adhesive systems that offer extra adhesion to the dentin (20, 29), alloy reattachment of fractured fragment to acquire characteristic of non invasive method of treatment with good results. Beveling, chamfers, notching and over contouring cannot change this prognoses (6).

Dean et al. (14) explore the influence of mode of preparation upon fracture resistance of reattached fragments. They conclude that 45-degree bevel doesn't increase tooth's strength. Fractured teeth reattached without preliminary preparation have shown resistance as those beveled 45-degrees. Worthington et al. (36) show similar results. In the study they make internal and external bevels in the fragment and the remaining tooth and stand that the retentions made do not increase fracture resistance. The authors even point out that addition of resin in the bonded area do not increase fracture resistance compared to the group of teeth reattached only with bonding agent.

The results of published in 2001 experimental investigation of Reis et al are contrary (30). The authors conclude that only reattachment of fractured fragment can not reach the strength obtained by preparation of enamel bevel, internal enamel or dentin chamfers or over contouring. According to Reis et al. Tooth reattachment without additional preparation restores only $37,1 \%$ of the intact teeth strength, while preparation of buccal chamfer restores 60 , and $6 \%$ of this strength. When reattaching with and preparation of internal dentin chamfer are restored 97, 2\% and $90,5 \%$ respectively from the strength of the intact teeth. Here are related the results of Demarco et al in 2004. According to their opinion presence of bevel increases fracture resistance of all materials used (15). Some authors think that the methods described disturb exact adaptation of fragment to the tooth. That's why they prepare chamfer after reattachment and fill it with resin (3). It's also a method for masking the visible reattachment line.

Materials used for reattachment of fractured teeth are investigated from many clinicians for they also influence strength of the connection tooth structure - fragment. While Kanca and Baratieri et al. Use dentin bonding systems All Bond 2 (Bisko Dental, USA) and Scotchbond Multipurpose (3M Dental, USA) $(6,22)$ respectively, other authors apply alternative resources for fragment reattachment. Baratieri et al. Describe usage of glass ionomer cements and resin the so cold "sandwich technique" (5). Another alternative is the adhesive system on the basis of 4-metacriloxietil trimetilat anhydride in combination with 3 -n-butyl borate (4-META). The material shows high connection strength to enamel and 
dentin and some clinicians use it as fragment reattachment (10). Development of contemporary composite materials and the possibilities of modern adhesive dentistry are reason for new investigations connected with reattachment technique $(6,24)$. Andreasen FM et al. (4) pointed out that material with comparatively high mechanical properties as composite resin should be used in combination with adhesives to outstand the functional loading. Andreasen FM et al. published in 1995 a multicentered clinical study investigating strength of reattached tooth fragments. Data come from three dental clinics both of which use only acid etching for fragment reattachment, while the third is adding a bonding agent plus acid etching. The results show that the retention level is high at fragments reattached with acid etching and bonding agent (3). In a contemporary study of Farik et al (19) it is confirmed that most bonding systems fifth generation increase fracture resistance of reattached crown fragments when used in combination with resin. Selfetching adhesives have lower fracture resistance at reattachment compared to the adhesives with components in different bottles (multibottled) (35).

In spite the conflicting results addition of composite material is important it cases when the adaptation between fragment and tooth is not sufficient and when the connection line is too visible but the patient insists for better esthetics.

Sometimes the fracture comprises enormous part of the dentin and full polymerization is difficult to achieve (30). In these cases chemically polymerized or double polymerized materials are preferred Dean et al (14) and Reis et al. (30) don't find statistically significant difference between photo and chemically polymerized composite materials for reattachment of fractured fragments. Some authors recommend usage of preliminary made silicon matrix that will maintain the correct positioning of the fragment (2).

\section{- Prognosis}

Stability of reattached tooth fragments is difficult to provide for. There is a lack of enough clinical long lasting studies. The clinical trail of Andreasen et al. (3) for lasting retention of adhesively reattached fragment concludes that good retention of the fragment; satisfied esthetics and preservation of pulp vitality make usage of crown fragment realistic alternative of composite build up. The authors follow up clinically 334 reattached fractured incisors and receive $50 \%$ and $25 \%$ retention after 2,5 and 7 years respectively. In another clinical investigation Cavallieri и Zerman (12) compare two different ways of treatment of crown fractures - direct adhesive build up and reattachment of tooth fragment After 5 years of follow up more stabile esthetic results are achieved at application of fragment reattachment. Another prospective investigation made upon 50 reattached incisor fragments shows $80 \%$ level of "survival" after 5 years. The authors use acid etching, internal $\mathrm{V}$-shaped channels, bonding agents and photopolimerized resin (34).

In a contemporary clinical study after 2 years of follow up of reattached fractured incisors of 11 children aged 8-13, the authors receive „satisfying” and ,very satisfying" clinical and roentgen results concerning periodontal, pulpal, color harmony and occlusion (37).

Using the good experience of the published in the articles there are more often scientific reports of successfully followed up clinical cases of reattached fractured teeth without pulp involvement (1) or of endodontically treated teeth $(17,23)$.

\section{CONCLUSION}

Crown fractures of the permanent teeth in schoolchildren are unique to a great extend and can not be easily classified according to the way of reconstruction. Literally application of separate method is difficult and every clinician has to know a number of methods for reconstruction. Reattachment of tooth fragment is minimal invasive and esthetic method. The approach is conservative and that is way with great evidence for reconstruction of crown fractures at schoolchildren. This method proposes to the dental clinicians' different opportunities for esthetic and functional restorations that are economically effective at the same time. Essential advantage of the reattached teeth is the fact that all the alternative methods as direct adhesive resin reconstruction, veneers and crowns can be performed in case of failure.

\section{REFERENCE}

1. А. Белчева, Е. Илиева. Възстановяване на фрактурирани постоянни резци чрез използване на запазен зъбен фрагмент, Стоматолог 21. 2002, III, 3:31-33. [in Bulgarian]

2. Alvares I, et al. Silicone index: an alternative approach for tooth fragment reattachment. J Esthet Restor Dent 2007;19(5):240-5.

/ J of IMAB, 2008, vol. 14, issue 2/
3. Andreasen FM, Noren JG, Andreasen JO, et al. Long term survival of fragment bonding in the treatment of fractured crowns: a multicenter clinical study. Quintessence Int 1995; 26: 669681.

4. Andreasen FM, Sternhardt U, Bille M, Munksgaard EL. Bonding of enamel-dentine crown fragments after crown fracture. An experimental study using bonding agents. Endod Dent Traumatol 1993; 9: 111-114.

5. Baratieri LN, Monteiro S Jr, Caldeira de Andrada M. The "sandwich" technique as a base for reattachment of dental fragment. Quintessence Int 1991; 22: 81-85.

6. Baratieri LN, Ritter AV, Monteiro 
S Jr, et al. Tooth fragment reattachment: An alternative for restoration of fractured anterior teeth. Pract Periodontics Aesthet Dent 1998; 10: 115-125.

7. Basuttil NA, Fung DE. Tooth fragment reattachment after retrieval from the lower lip - a case report. Dent Traumatol 2007; 23: 177-180.

8. Borssen E, Holm AK. Traumatic dental injuries in a cohort of 16-yearolds in northern Sweden. Endod Dent Traumatol 1997; 13: 276-280.

9. Burke FJT. Reattachment of fractured central incisor tooth fragment. Br Dent J 1991; 170: 223-225.

10. Burke FJT. Repair of fractured incisors using a 4-META material. Dent Update 1997; 24: 358-360.

11. Capp CI, Roda MI, Tamaki R et al. Reattachment of rehydrated dental fragment using two techniques. Dent Traumatol 2009; 25: 95-99.

12. Cavalleri G, Zerman N. Traumatic crown fractures in permanent incisors with immature roots: a follow-up study Endod Dent Traumatol 1995: 11: 294-296.

13. Chosack A, Eildeman E. Rehabilitation of fractured incisor using the patient's natural crown. Case report. J Dent Child 1964;31: 19-21.

14. Dean JA, Avery DR, Swartz ML. Attachment of anterior tooth fragments. Pediatr Dent 1986; 19: 731-743.

15. Demarco FF, Fay R-M, Pinzon LM, et al. Fracture resistance of reattached coronal fragments - influence of different adhesive materials and bevel preparation. Dent Traumatol 2004; 20: 157-163.

16. DiAngelis AJ, Jungbluth MA. Restoration of amputated crown by acid - etched technique. Quintessence Int 1987; 18: 829-833.
17. El-Askary FS, et al. Reattachment of a severely traumatized maxillary central incisor, one-year clinical evaluation: a case report. J Adhes Dent. 2006 Oct;8(5):343-9.

18. Farik B, et al. Drying and rewetting anterior crown fragment prior to bonding. Endod Dent Traumatol 1999; 15: 113-116.

19. Farik B, et al. Fractured teeth bonded with dentine adhesives with and without unfilled resin. Dent Traumatol 2002; 18: 66-69.

20. Gallo JR, et al. Shear bond strength of four filled dentine bonding systems. Oper Dent 2001; 26:44-47.

21. Hall DA. Restoration of shattered tooth. J Am Dent Assoc 1998; 129:105-106.

22. Kanca J. Replacement of a fractured incisor fragment over pulp exposure: a case report. Quintessence Int 1993; 24: 81-84.

23. Karapanou V, Antonellou E.J Mass. Autogenous attachment technique with esthetics in mind: trauma management case report. Dent Soc.2008;56(4):32-5.

24. Liebenberg WH. Reattachment of a coronal fragment: operative considerations. Pract Periodont Aesth Dent 1997; 9: 761-772.

25. Macedo GV et al. Reattachment of anterior teeth fragments: a conservative approach. J Esthet Restor Dent. 2008;20(1):5-18.

26. Magne P, Douglas WH. Cumulative effects of successive restorative procedures on anterior crown flexure: intact versus veneered incisors. Quintessence Int 2000; 31:5-18.

27. Osborne J, Lambert R. Reattachment of incisor tooth fragment. Gen Dent 1985; 33: 516-517.

28. Perdigro J, Lopes M. Dentin
bonding-State of the art 1999. CompContin Educ Dent 1999; 20:11511162.

29. Perdigro J, Swift EJ Jr, Gomes J et al. Bonding strength of new simplified dentin enamel adhesives. Am J Dent 1999; 12: 286-290.

30. Reis A, Francci C, Lognercio $\mathrm{AD}$, Carrilho MRO, Rodrigues Filho LE. Re-attachment of anterior fractured teeth: fracture strength using different techniques. Oper Dent 2001; 26:287294.

31. Reis A, Kraul A, Francci C et al. Re-attachment of fractured teeth: a review of literature regarding techniques and materials. Oper Dent 2004; 29:295-300.

32. Strassler HE. Aesthetic management of traumatized anterior teeth. Dent Clin North Am1995; 39: 181-204.

33. Trushkowsky RD. Esthetic, biologic and restorative considerations in coronal segment reattachment for a fractured tooth: A clinical report. J Prosthetic Dent 1998; 79: 115-119.

34. Vijayakumaran V. Evaluation of crown restoration of fractured anterior teeth using original tooth fragment. J Dent Res 1998; 77: 696.

35. Wiegand A, Rodig T, Attin T. Treatment of crown fructured incisors: reattachment instead of restoration? Schweiz Monatsschr Zahnmed 2005; 115: 1172-1181.

36. Worthington RB, Murchinson DF, Vanderwalle KS. Incisor edge reattachment: The effect of preparation utilization and design. Quintessence Int 1999; 30: 637-645.

37. Yilmaz $\mathrm{Y}$ et al, Evaluation of success in the reattachment of coronal fractures. Dent Traumatol. 2008 Apr; 24(2):151-8.

Address for correspondence:

Dr. Ani Beltcheva, PhD

Department of Pediatric Dentistry, Faculty of Dental Medicine,

Medical University, Plovdiv, Bulgaria

E-mail: abeltcheva@yahoo.com 